\title{
Esophageal pressure balloon and transpulmonary pressure monitoring in airway pressure release ventilation: a different approach
}

\author{
Ehab G. Daoud, MD, FACP, FCCP1,2,3, Kimiyo H. Yamasaki, RRT ${ }^{4}$, Keith Nakamoto, RRT ${ }^{4}$, Denise Wheatley, RRT ${ }^{4}$
}

\begin{abstract}
EG Daoud, KH Yamasaki, K Nakamoto, D Wheatley. Esophageal pressure balloon and transpulmonary pressure monitoring in airway pressure release ventilation: a different approach. Can J Respir Ther 2018;54(3):62-65. doi: 10.29390/cjrt-2018-010.

This is a case of Acute Respiratory Distress Syndrome managed using esophageal balloon catheter to adjust inspiratory pressure and positive end expiratory pressure according to the inspiratory and expiratory transpulmonary pressures. There are no studies that examine the transpulmonary pressures in airway pressure release ventilation (APRV). We aimed to test the feasibility of using the esophageal balloon in the nonconventional mode of APRV. All pressures were observed when switching the mode from a pressure-controlled mode to APRV using the same inspiratory pressure and using various incremental release times $\left(\mathrm{T}_{\mathrm{Low}}\right)$ to calculate the expiratory transpulmonary pressure. At all $\mathrm{T}_{\mathrm{Low}}$ levels the transpulmonary pressure at end exhalation was in the negative value indicating alveolar collapse. A larger study is needed to confirm our findings and to help guide setting APRV.
\end{abstract}

Key Words: esophageal balloon; transpulmonary pressure; APRV; PEEP

\section{INTRODUCTION}

The use of esophageal pressure monitoring as a surrogate for pleural pressure and, hence, the transpulmonary pressure $\left(\mathrm{P}_{\mathrm{L}}\right)$, which is the distending pressure of the lungs, was described in the mid-20th century. This technology has many benefits in different clinical situations during mechanical ventilation, for example to assess patient's effort when the respiratory muscles are active, to monitor the patient-ventilator interactions, and to facilitate the weaning process from mechanical ventilation $[1,2]$. However, its use has been mostly limited to clinical research [1]. The recent international Safe Lung study [3] revealed that such technology is rarely used in Acute Respiratory Distress Syndrome (ARDS) patients. Increased interest in using such technology arose after a 2008 study [4] used esophageal pressure monitoring to set inspiratory pressures and positive end expiratory pressure (PEEP) in ARDS using the transpulmonary pressure $\left(\mathrm{P}_{\mathrm{L}}\right)$. According to the study protocol, the end inspiratory $\mathrm{P}_{\mathrm{L}}$ was kept under $25 \mathrm{cmH}_{2} \mathrm{O}$ and the end expiratory $\mathrm{P}_{\mathrm{L}}$ between 0 and $10 \mathrm{cmH}_{2} \mathrm{O}$. Using such a strategy resulted in improved oxygenation, compliance, and trend towards improved mortality. Our understanding of ventilator-induced lung injury (VILI) has markedly advanced over the last decade [5]. The use of the esophageal balloon monitoring during mechanical ventilation is most appealing and has a physiologically sound base to avoid lung stress and strain, thus reducing VILI. Given those benefits, many ventilator manufacturers have incorporated esophageal pressure monitoring in their products. To our knowledge, this strategy has not been duplicated in any of the nonconventional modes of ventilation such as airway pressure release ventilation (APRV). We aimed to test the esophageal balloon in APRV and the resultant $\mathrm{P}_{\mathrm{L}}$, especially the end expiratory $\mathrm{P}_{\mathrm{L}}$, with different release times $\left(\mathrm{T}_{\text {Low }}\right)$.

Introduced in the mid-1980s, APRV is considered by many as a nonconventional mode of ventilation [6]. APRV is an inverse ratio, pressure controlled, intermittent mandatory ventilation with unrestricted spontaneous breathing [7] that is mainly used as an alternative mode of ventilation in the difficult to oxygenate patient. APRV has many potential benefits described elsewhere [5] and beyond the scope of this paper. Briefly, it is the use of a long inspiratory pressure phase $\left(\mathrm{P}_{\text {High }}\right)$ that maintains alveolar recruitment. In addition, the expiratory pressure phase $\left(\mathrm{P}_{\mathrm{Low}}\right)$ and the release time $\left(\mathrm{T}_{\mathrm{Low}}\right)$ are kept very short to create auto-PEEP and to prevent end expiratory volume loss and alveolar derecruitment [8]. However, setting APRV has been a subject of much debate [7], especially the lack of consensus regarding its settings [9].

\section{Patient and Methods}

No ethics review committee approval was needed given the nature of the case report. The patient signed an approval to publish the case, and no personal information or photographs of the patient were included.

A 61-year-old obese male was admitted to the hospital with bilateral severe community-acquired pneumonia leading to acute respiratory failure and severe ARDS with $\mathrm{PaO}_{2} / \mathrm{FiO}_{2}$ of 75 . He was managed with pressure-targeted controlled mechanical ventilation (PCV-CMV), to target a tidal volume (VT) $6 \mathrm{~mL} / \mathrm{kg}$ ideal body weight, and PEEP was adjusted to $15 \mathrm{cmH}_{2} \mathrm{O}$ to maintain oxygen saturation of $90 \%$. However, because of high oxygen requirements $\left(\mathrm{FiO}_{2}\right)$, an esophageal balloon was inserted according to the manufacturer's guidelines (Hamilton Medical AG, Switzerland). The ventilator settings were adjusted to keep inspiratory $\mathrm{P}_{\mathrm{L}}$ below $20 \mathrm{cmH}_{2} \mathrm{O}$ and expiratory $\mathrm{P}_{\mathrm{L}} \mathrm{O}-5 \mathrm{cmH}_{2} \mathrm{O}$ (Figure 1).

The ventilator mode was changed to APRV as follows: $\mathrm{P}_{\text {High }}$ was set to $30 \mathrm{cmH}_{2} \mathrm{O}$ (same as inspiratory pressure on PCV), $\mathrm{P}_{\text {Low }}$ was set at $0 \mathrm{cmH}_{2} \mathrm{O}, \mathrm{T}_{\mathrm{Low}}$ started at $0.1 \mathrm{~s}$ and increased by increments of 0.1 to $0.7 \mathrm{~s}$, the release number was $10 \mathrm{~s}$, with each cycle $6 \mathrm{~s}$. $\mathrm{T}_{\text {High }}$ was variable from 5.9 to $5.3 \mathrm{~s}$ relative to the incremental increased $\mathrm{T}_{\text {Low }}$. We measured and recorded the airway pressure, esophageal pressure, inspiratory and expiratory $\mathrm{P}_{\mathrm{L}}, \mathrm{VT}$, expiratory flow, and percentage decay of expiratory flow from peak expiratory flow $(\mathrm{PEF})$ at the end of the $\mathrm{T}_{\text {Low }}$. Each setting was recorded for $2 \mathrm{~min}$.

${ }^{1}$ John Burns School of Medicine, University of Hawaii, Honolulu, Hawaii, USA

${ }^{2}$ Respiratory Care Program, Kapiolani Community College, Honolulu, Hawaii, USA

${ }^{3}$ Intensive Care Department, Castle Medical Center, Kailua, Hawaii, USA

${ }^{4}$ Respiratory Department, Castle Medical Center, Kailua, Hawaii, USA

Correspondence: Ehab G. Daoud, Tel.: (440) 655-9697, Respiratory Department, Castle Medical Center, 640 Ulukahiki St Kailua, Hawaii, 96734 USA.

E-mail: ehab_daoud@hotmail.com

This open-access article is distributed under the terms of the Creative Commons Attribution Non-Commercial License (CC BY-NC) (http:// creativecommons.org/licenses/by-nc/4.0/), which permits reuse, distribution and reproduction of the article, provided that the original work is properly cited and the reuse is restricted to noncommercial purposes. For commercial reuse, contact editor@csrt.com 


\section{FIGURE 1}

Ventilator graphics display during pressure-controlled ventilation. On the $X$ axis from top to bottom: airway pressure, esophogeal pressure, and transpulmonary pressure, all in $\mathrm{cmH}_{2} \mathrm{O}$. $\mathrm{Y}$ axis is time in seconds.

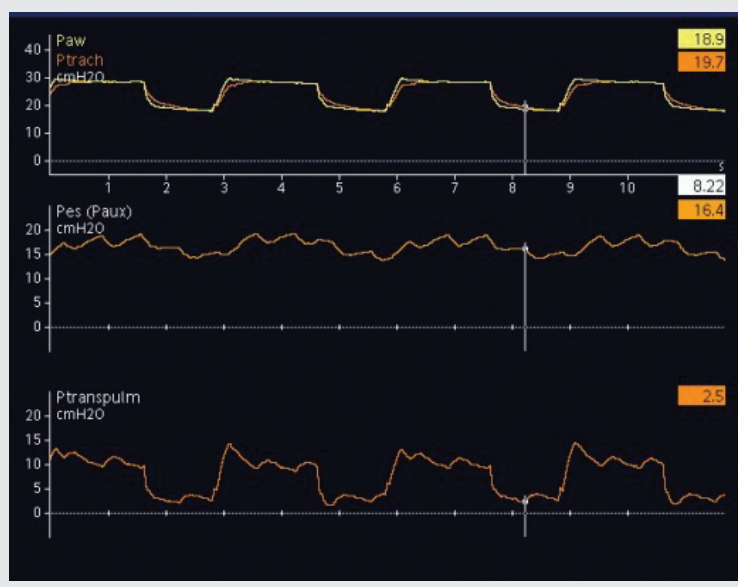

\section{RESULTS}

The results are summarized in Figure 2 and Table 1. At all levels of $\mathrm{T}_{\text {Low }}$ from 0.1 to $0.7 \mathrm{~s}$, the expiratory $\mathrm{P}_{\mathrm{L}}$ was constantly a negative value indicating alveolar collapse. The expiratory flow at the end of the releases ranged from $75 \%$ to $87 \%$.

\section{DISCUSSION}

The concept of using an esophageal pressure monitoring to guide setting mechanical ventilation, especially PEEP, has been on the rise and gaining momentum over the last decade. Research has shown that setting PEEP during conventional mechanical ventilation to maintain a positive $\mathrm{P}_{\mathrm{L}}$ at end of expiration improves oxygenation, respiratory compliance, and the trend towards improved mortality [4]. No such research was duplicated with the use of APRV. APRV setting, especially $\mathrm{T}_{\text {Low }}$, has been the subject of much debate and confusion. The concept of $T_{\text {Low }}$ is to create a short release time creating auto-PEEP to avoid volume loss and alveolar dercruitment at end of expiration. In our 2012 review article [7], we described in detail the different methods of setting $T_{\text {Low }}$ in APRV with the relative advantages and disadvantages of each method. Briefly, it has been suggested to set $\mathrm{T}_{\text {Low }}$ empirically in a range of $0.2-0.8 \mathrm{~s}[8,10]$, but some have advocated to set it to achieve $50 \%-75 \%$ of PEF [8]. Another study suggested to set it according to a certain time constant $(\tau)$ (calculated as the product of the static respiratory compliance and resistance) and to adjust it for a certain tidal volume per release [11]. DiRocco et al. [12] suggested that alveolar

\section{FIGURE 2}

Ventilator graphics display during APRV showing summary of airway pressure, esophogeal pressure, transpulmonary pressure, all in $\mathrm{cmH}_{2} \mathrm{O}$ and flow in L/min, on $\mathrm{X}$ axis during different release times $(0.1-0.7 \mathrm{~s})$. $\mathrm{Y}$ axis is time in seconds.
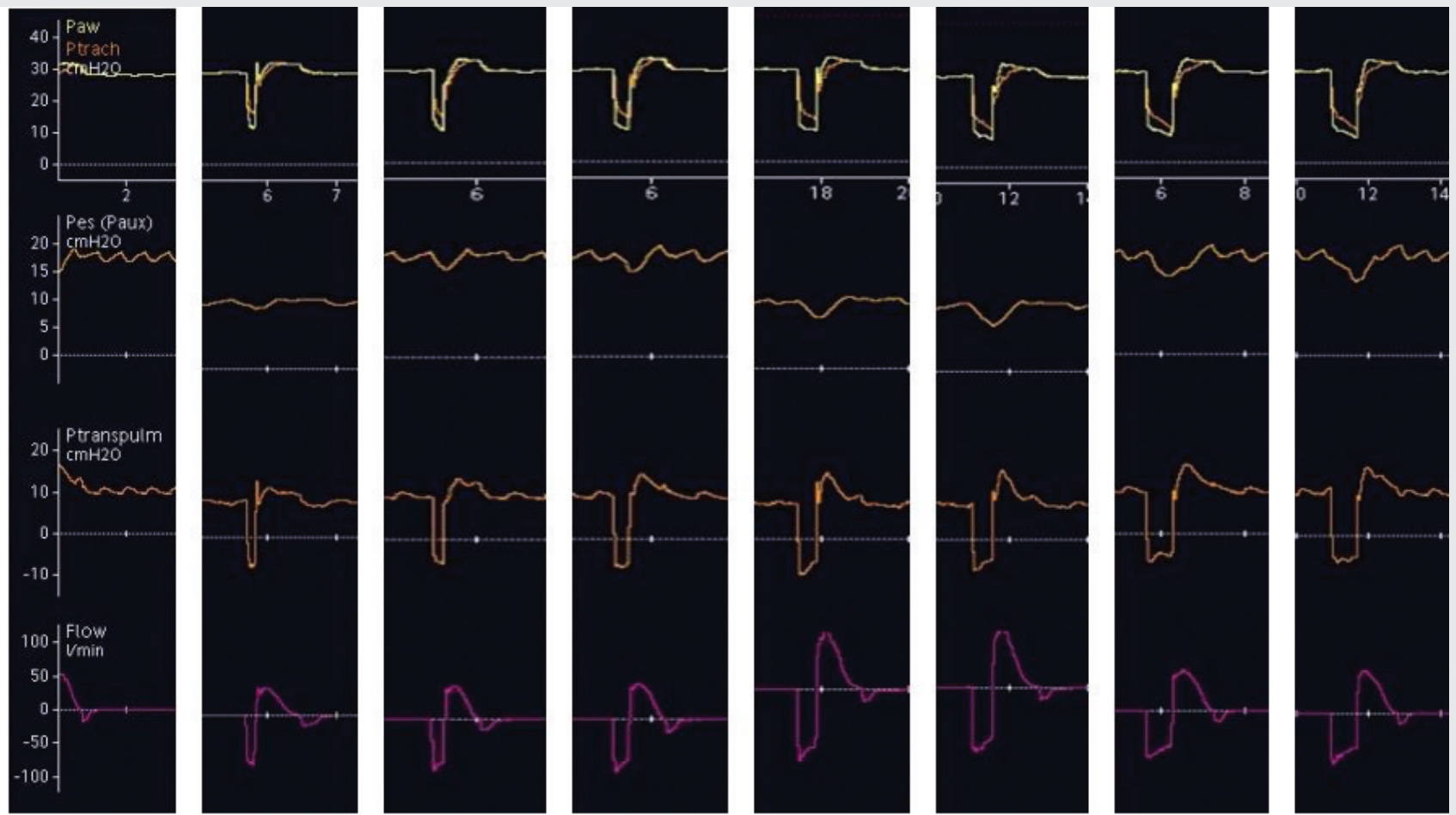

0.1

0.2

0.3

0.4

0.5

0.6

0.7

\section{T Low (seconds)}


derecruitment still occurs despite short release time in APRV in an animal model of lung injury.

We previously found that the expiratory flow decay and, hence, auto-PEEP created during APRV is variable depending on the ventilator manufacturer and thus may not be reliable [13]. Similarly, another bench study that compared three different methods of setting $T_{\text {Low }}$ described the challenges and the unpredictability of autoPEEP in APRV [14].

In a recently published APRV review [15], we called for research using innovative ways to set APRV, including the use of esophageal pressure monitoring or measuring the functional residual capacity. To our knowledge this is the first attempt to investigate the $\mathrm{P}_{\mathrm{L}}$ in APRV. KollischSingule et al. [16] recently used esophageal balloon monitoring in APRV to monitor respiratory mechanics in an animal model of extrapulmonary lung injury with no mention of $\mathrm{P}_{\mathrm{L}}$ during the $\mathrm{T}_{\text {Low }}$

Our case is just "food for thought" and hopefully will encourage more research into this controversial and critical aspect of setting APRV. An intriguing observation in our case is that the esophageal pressure change during the release did not parallel the airway pressure (Figure 2) though as expected the drop increased steadily from 0.1 to $0.7 \mathrm{~s}$ because of the different compliances and resulting time constants between the lung and the chest wall. Our patient's total respiratory system compliance $\left(\mathrm{C}_{\mathrm{RS}}\right)$, calculated as the tidal volume divided by plateau pressure (obtained during brief inspiratory pause) - total PEEP, was $50 \mathrm{~mL} / \mathrm{cmH}_{2} \mathrm{O}$; the chest wall compliance $\left(\mathrm{C}_{\mathrm{CW}}\right)$, calculated as tidal volume divided by esophageal/pleural pressure $\left(\mathrm{P}_{\mathrm{PL}}\right)$, was $29 \mathrm{~mL} / \mathrm{cmH}_{2} \mathrm{O}$; and finally lung compliance $\left(\mathrm{C}_{\mathrm{L}}\right)$, calculated as $\mathrm{C}_{\mathrm{RS}}-\mathrm{C}_{\mathrm{CW}}$,was $21 \mathrm{~mL} / \mathrm{cmH}_{2} \mathrm{O}$ (Figure 3). The worst compliance of the lung would mean faster emptying and collapse compared with the higher chest

TABLE 1

\section{Patient test results}

\begin{tabular}{lccccccc}
\hline & \multicolumn{8}{c}{$\mathrm{T}_{\text {Low }}(\mathbf{s})$} \\
\cline { 2 - 8 } & $\mathbf{0 . 1}$ & $\mathbf{0 . 2}$ & $\mathbf{0 . 3}$ & $\mathbf{0 . 4}$ & $\mathbf{0 . 5}$ & $\mathbf{0 . 6}$ & $\mathbf{0 . 7}$ \\
\hline Airway pressure $\left(\mathrm{cmH}_{2} \mathrm{O}\right)$ & 11 & 10 & 10 & 9 & 9 & 8 & 8 \\
Esophogeal pressure $\left(\mathrm{cmH}_{2} \mathrm{O}\right)$ & 18 & 17 & 15 & 14 & 14 & 13 & 12 \\
Transpulmonary pressure $\left(\mathrm{cmH}_{2} \mathrm{O}\right)$ & -7 & -7 & -5 & -5 & -5 & -5 & -4 \\
$\%$ PEF & 87 & 85 & 83 & 81 & 80 & 78 & 75 \\
\hline
\end{tabular}

$\% \mathrm{PEF}$, percentage of decay of peak expiratory flow at the end of the release time; $\mathrm{T}_{\text {Low }}$, time low or release time in seconds.

\section{FIGURE 3}

Ventilator graphics display during volume-controlled ventilation with an inspiratory hold maneuver to calculate the static compliance of respiratory system and airway resistance. On the $X$ axis from top to bottom: airway pressure, esophogeal pressure, and transpulmonary pressure all in $\mathrm{cmH}_{2} \mathrm{O}$. $\mathrm{Y}$ axis is time in seconds.

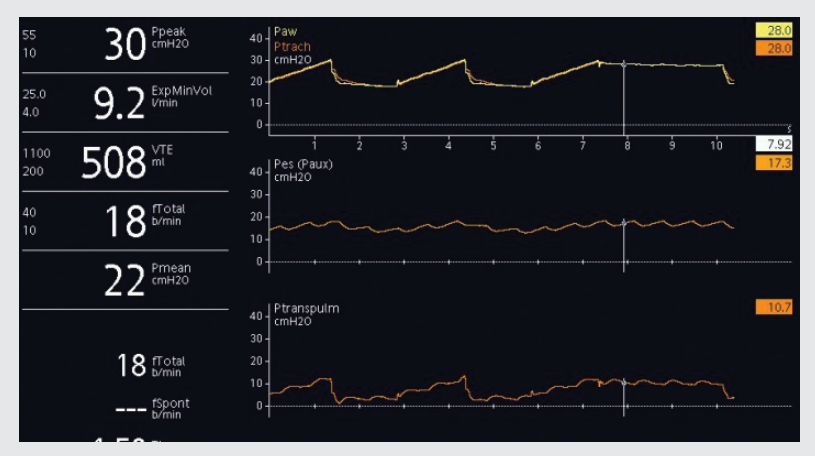

wall compliance. Furthermore, an important issue not to be missed, as our patient $\tau$ was $0.2 \mathrm{~s}$ (calculated as compliance $\times$ resistance, i.e., $0.05 \mathrm{~L} / \mathrm{cmH}_{2} \mathrm{O} \times 4 \mathrm{cmH}_{2} \mathrm{O} / \mathrm{L} / \mathrm{s}$ ), the expiratory flow did not decay by $63.2 \%$ each $0.2 \mathrm{~s}$ to almost reach zero at 4 time constants of $0.8 \mathrm{~s}$ as expected per a mathematical method previously published [7] (Figure 4).

\section{FIGURE 4}

Lung simulator diagram of airway pressure release ventilation: volume (yellow), lung pressure (white), and flow (orange)/time curve. Time constant (TC) was known and the $T_{\text {Low }}$ was set to more than $4 \mathrm{TCs}$. The blue vertical lines represent each TC. Intrinsic PEEP at each TC would be equal to the point intersecting with the pressure curve, or it can be calculated as the end expiratory lung volume divided by respiratory compliance. Notice that at each TC the flow curve did not decay to $36.2 \%$ from its previous value as expected per the mathematical model. Reproduced with permission from Respiratory Care [5].

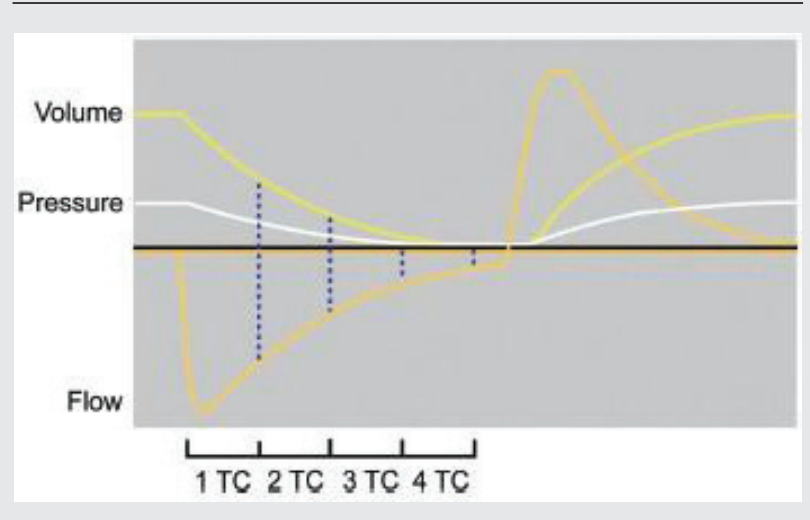

\section{FIGURE 5}

Ventilator graphic display during APRV with an expiratory hold maneuver to calculate auto-PEEP, total PEEP, and end expiratory transpulmonary pressure at the end of the release time. On the $X$ axis from top to bottom: airway pressure, esophageal pressure, and transpulmonary pressure all in $\mathrm{cmH}_{2} \mathrm{O}$ and flow in L/min. $\mathrm{Y}$ axis is time in seconds.

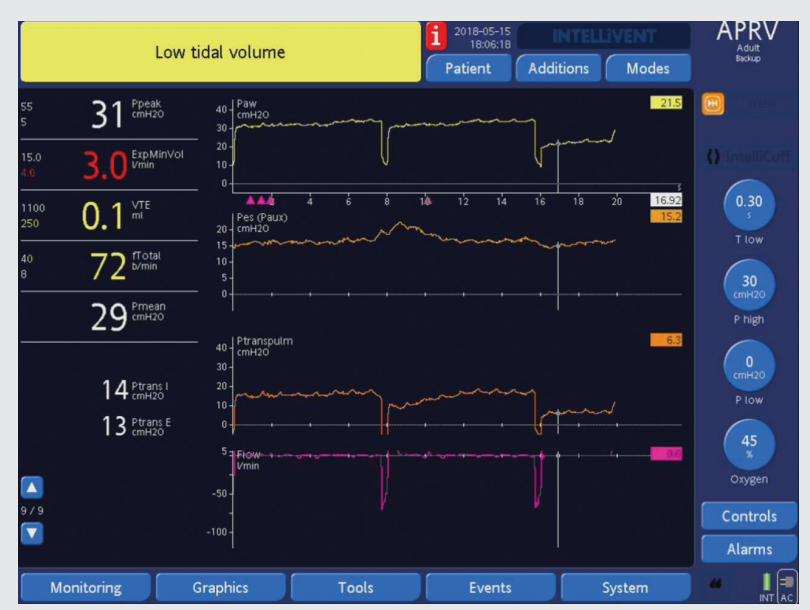


This finding confirms our previous observation that the flow decay differs with the ventilator model and from the mathematical theory to the bedside [13]; therefore, using the time constant to set $\mathrm{T}_{\text {Low }}$ may not be accurate.

Our case has some limitations in addition to the inherit limitation of the esophageal balloon pressure monitoring. (i) This is a single patient report with a short observation time. (ii) The $\mathrm{P}_{\text {High }}$ and the $\mathrm{T}_{\text {Low }}$ were kept constant and were not adjusted, so consequently the $\mathrm{T}_{\text {High }}$ got shorter each time the $T_{\text {Low }}$ was increased. In retrospect we might have needed to change those variables to evaluate if that would have an effect on the expiratory $P_{L}$. (iii) The exact amount of auto-PEEP in APRV is hard to obtain or calculate at the bedside, and doing an expiratory hold maneuver at the end of the release was never documented as the accepted way to measure total PEEP or the auto-PEEP if using $\mathrm{P}_{\text {Low }}$ of $0 \mathrm{cmH}_{2} \mathrm{O}$. Consequently, we did not apply an expiratory hold at the end of the release. Figure 5 shows an expiratory hold maneuver in a different patient on APRV.

The expiratory $\mathrm{P}_{\mathrm{L}}$ is negative using the airway pressure at the $\mathrm{T}_{\text {Low' }}$ but it is positive at the end of the expiratory hold. In theory, calculating the $\mathrm{P}_{\mathrm{L}}$ after the expiratory pause is the most appropriate way to set the $\mathrm{T}_{\text {Low }}$. This dilemma needs to be further investigated.

Hopefully new research and observations take into account these limitations.

\section{CONCLUSION}

Setting APRV, especially the $T_{\text {Low }}$, with the aid of esophageal balloon to measure $\mathrm{P}_{\mathrm{L}}$ is conceptually valuable and relatively feasible.

Setting $\mathrm{T}_{\text {Low }}$ in APRV according to the percentage of PEF might not be a valid method of avoiding alveolar collapse. More studies are needed to confirm these findings.

\section{REFERENCES}

1. Akoumianaki E, Maggiore SM, Valenza F, Bellani G, Jubran A, Loring $\mathrm{SH}$, et al., The application of esophageal pressure measurement in patients with respiratory failure. Am J Respir Crit Care Med 2014;189(5): 520-31.

2. Takeshi Yoshida T, Brochard L, Esophageal pressure monitoring: Why, when and how?. Curr Opin Crit Care 2018;24(3): 216-22. doi: 10.1097/ MCC. 0000000000000494
3. Bellani G, Laffey JG, Pham T, Fan E, Brochard L, Esteban A, et al., Epidemiology, patterns of care, and mortality for patients with acute respiratory distress syndrome in intensive care units in 50 countries. JAMA 2016;315(8): 788-800. doi: 10.1001/jama.2016.0291

4. Talmor D, Sarge T, Malhotra A, O'Donnell CR, Ritz R, Lisbon A, et al. Mechanical ventilation guided by esophageal pressure in acute lung injury. N Engl J Med 2008;359(20): 2095-104

5. Slutsky AS, Ranieri VM, Ventilator-induced lung injury. N Engl J Med 2013;369(22): 2126-36

6. Stock MC, Downs JB, Frolicher DA, Airway pressure release ventilation. Crit Care Med 1987;15( 5):462-6. doi: 10.1097/00003246-19870500000002.

7. Daoud EG, Farag HL, Chatburn RL, Airway pressure release ventilation: What do we know?. Respir Care 2012;57(2): 282-92

8. Habashi NM, Other approaches to open-lung ventilation: Airway pressure release ventilation. Crit Care 2005;Med 33: Suppl 3S228-40

9. Miller AG, Gentile MA, Davies JD, MacIntyre NR, Clinical management strategies for airway pressure release ventilation: A survey of clinical practice. Respir Care 2017;62(10): 1264-8. doi: 10.4187/respcare. 05494.

10. Daoud EG, Airway pressure release ventilation. Ann Thorac Med 2007;2(4): 176-9. doi: 10.4103/1817-1737.36556

11. Terragni PP, Rosboch GL, Lisi A, Viale AG, Ranier VM, How respiratory system mechanics may help in minimizing ventilator induced lung injury in ARDS patients. Eur Respir J 2003;22: Suppl 4215S-21S. doi: 10.1183/09031936.03.00420303.

12. DiRocco J, Carney D, Boubert F, McBride N,, Hojnowski K, et al., Short expiratory time with pressure-release ventilation are inadequate to prevent alveolar derecruitment in surfactant-depleted lung. Respir Care 2005;50(11): 1520.

13. Daoud E, Chatburn RL, Auto-PEEP during APRV varies with the ventilator model. Respir Care 2010;55(11): 1516

14. Mireles-Cabodevila E, Siddiqui MF, Chatburn RL, Comparison of three methods to set $\mathrm{T}$ low on airway pressure release ventilation - a model study. Respir Care 2010;55(11): 1571

15. Daoud EG, Airway pressure release ventilation: Translating clinical research to the bedside in acute respiratory distress syndrome. Crit Care Shock 2015;18(1): 7-15

16. Kollisch-Singule M, Emr B, Jain SV, Andrews P, Satalin J, Liu J, et al., The effects of airway pressure release ventilation on respiratory mechanics in extrapulmonary lung injury. Intensive Care Med Exp 2015;3(1): 35. doi: 10.1186/s40635-015-0071-0. 